\title{
Chicken Dead End Homologue Protein is a Nucleoprotein of Germ Cells Including Primordial Germ Cells
}

\author{
Shinya ARAMAKI'), Kaiyu KUBOTA ${ }^{1}$, Tomoki SOH ${ }^{1)}$, Nobuhiko YAMAUCHI') and \\ Masa-aki HATTORI ${ }^{1)}$ \\ ${ }^{1)}$ Department of Animal and Marine Bioresource Sciences, Graduate School of Agriculture, Kyushu University, Fukuoka \\ 812-8581, Japan
}

\begin{abstract}
The dead end gene, coding an RNA binding protein, is predominantly expressed in the germ cells of vertebrates. Recently, we cloned chicken dead end homologue $(\mathrm{CDH})$ and showed that expression of CDH mRNA is highly specific to primordial germ cells (PGCs) at early embryonic stages. To date, the subcelluler localization of Dead end protein in germ cell has been largely unknown due to lack of an antibody. Here, we raised a polyclonal antibody against chicken dead end homologue $(\mathrm{CDH})$ to elucidate its subcellular localization in the germ cells. For comparative studies with $\mathrm{CDH}$, a polyclonal antibody against chicken vasa homologue $(\mathrm{CVH})$, a well-known germ cell marker, was also raised. Immunoblotting analysis for $\mathrm{CDH}$ protein showed a single band with a molecular size of approximately 60 $\mathrm{kDa}$ in the ovarian and testicular proteins. Immunofluorescence studies revealed that CDH protein was exclusively localized in the nuclei of primordial germ cells (PGCs) and germ cells at later stages, while CVH was localized in the cytoplasm. Interestingly, the germ cells distributed at the basal sides of seminiferous epithelia, such as spermatogonia, were strongly positive to CDH protein. The current study provides novel evidence that CDH is a nucleoprotein of germ cells, including PGCs.
\end{abstract}

Key words: Anti-chicken dead end homologue (CDH) antibody, Chicken, Chicken dead end homologue (CDH), Primordial germ cell, Spermatogonia, Subcellular localization

(J. Reprod. Dev. 55: 214-218, 2009)

$\mathbf{T}^{\mathrm{s}}$ he dead end gene is an evolutionary conserved RNA binding protein that is mainly expressed in germ cells. It was at first discovered in zebrafish [1], and its homologues have been identified in other vertebrates, such as the mouse, chicken, and Xenopus [1-3]. To date, several experiments have been performed to evaluate the function of dead end from the perspectives of germ cell development and embryonic survival. Knockdown of dead end in zebrafish primordial germ cells (PGCs) by RNA morpholino antisense oligonucleotides results in abnormal migration and fragmentation of PGCs [1]. In mice, inactivation of the dead end (Dnd1) gene in the Ter strain resulted in a PGC deficiency that caused the mice to become sterile [3]. In addition to PGC depletion, the 129 mouse strain background shows increases in the incidences of testicular germ cell tumors and embryonic lethality increase due to loss of Dnd1 [3, 4]. A recent study showed that Dead end protein counteracts the function of several microRNAs (miRNAs) in human cells and zebrafish PGCs by binding to mRNAs and prohibiting miRNAs from associating with their target sites; this results in eventual protection of the expression of some genes expressed in germ cells [5]. In previous studies, subcellular localization of Dead end protein has been investigated by detecting GFP-Dead end fusion protein exogenously expressed in several cell types. Like Vasa, the fusion protein is localized in the perinuclear germ granules of zebrafish PGCs [1]. GFP-DND1 is localized in the cytoplasm of COS-7 cells, whereas it is localized in the nuclei

Accepted for publication: December 18, 2008

Published online in J-STAGE: February 5, 2009

Correspondence: M Hattori (e-mail: mhattori@agr.kyushu-u.ac.jp) of HeLa cells [4]. This suggests that the subcellular localization of Dead end protein depends on cell type. However, there is little in the literature concerning temporal localization and expression of Dead end protein during germ cell development. Likewise, the molecular mechanism that controls its localization remains unclear.

To further research in these areas, a highly specific antibody against Dead end protein is required for direct detection of the subcellular localization both in vivo and in vitro. More recently, we isolated a full length of chicken dead end homologue (CDH) cDNA from chicken PGCs [2]. Here, we produced a polyclonal anti-CDH antibody against recombinant $\mathrm{CDH}$ protein and immunohistochemically investigated the subcellular localization of $\mathrm{CDH}$ protein in germ cells from the embryonic to mature stages for comparison with that of $\mathrm{CVH}$ protein, one of the most reliable germ cell markers.

\section{Materials and Methods}

\section{Animals}

Fertilized eggs were purchased from a commercial breeder and incubated with intermittent rocking at 37-38 C under a relative humidity of $60-70 \%$. White Leghorn chickens (Gallus gallus domesticus) were maintained under a 14-h light / 10-h dark cycle with water and food ad libitum. All experiments were performed under the control of the Guidelines for Animal Experiments in the Faculty of Medicine, Kyushu University in accordance with the law (No. 105) and notification (No. 6) of the Government of Japan. 
(A) MAEEQTTSSINRTNKMALLAWVRETGIDLVQVNGQRRYGGPPPGWVGSPPPPGEVYIAK 60 LPRDLYEDTLIPLFQSVGQLYEFRLMLTFSGLNRGFAYAKYSDQHGAGKAIAALNNWEVQ 120 EGRAILVCRSFEKCELSVNGLPATLRRRELDTMLLEATEGLLGLTLHASPGRKQGKVAVL 180 TYSSHRAAAMAKKALVEGNVGLFKKKVKVEWLKPELKEQLOACGEKPPPGSVQCLQSPER 240 VIPSSEL RGALGPLGALCRL HIGTPPFL TRCYOAEPHGWORYWCOYVIPSYPVPCSTFL 300 WVREDAPGTVGHEKMKKEAVAQLALYMLGH
(B)

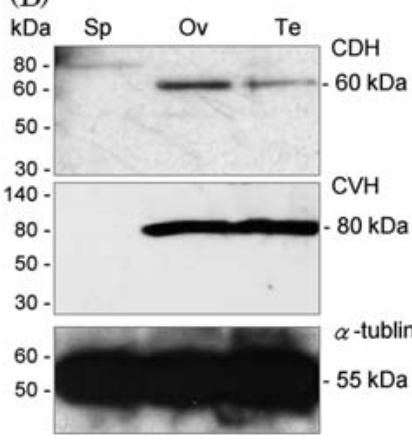

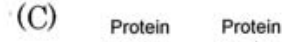

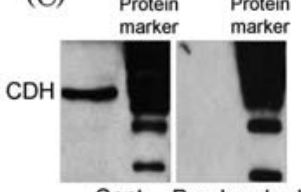

Cont Preabsorbed

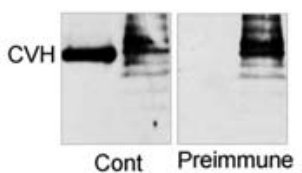

Fig. 1. Immunodetection of $\mathrm{CDH}$ and $\mathrm{CVH}$ proteins in the testis and ovary. Proteins (30 $\mu \mathrm{g})$ prepared from the testes (Te), ovaries (Ov) and spleens (Sp) of 2-week-old chickens were separated on SDS-PAGE and analyzed by immunodetection using anti-CDH antibody. A: The C-terminal region of recombinant $\mathrm{CDH}$ protein coding 112 amino acids (underlined) was synthesized for antigen. B: CDH (top) and $\mathrm{CVH}$ proteins (middle) were detected in the ovaries and testes of immature chickens. Alpha-Tubulin was used as the internal control (bottom). $\mathrm{C}$ : $\mathrm{CDH}$ and $\mathrm{CVH}$ proteins were not detected in the ovaries and testes of immature chickens using preabsorbed anti-CDH antibody or preimmune rat serum (right); a single band was detected using the antibodies (left).

\section{Preparation of CDH-GST fusion protein and its antibody}

Total RNA was extracted from both male and female gonads in E6 embryos by using Sepasol-RNA I Super (Nacalai Tesque, Kyoto, Japan). Total RNA (1 $\mu \mathrm{g})$ was subjected to reverse transcription (RT) at $37 \mathrm{C}$ for $1 \mathrm{~h}$ in $20 \mu \mathrm{l}$ of $1 \times \mathrm{RT}$ buffer containing $2 \mathrm{mM}$ of each dNTP, $0.4 \mu \mathrm{g}$ oligo(dT) $12-18$, $50 \mathrm{U}$ ribonuclease inhibitor and $200 \mathrm{U}$ M-MLV reverse transcriptase. In order to produce a C-terminal region of CDH protein coding 112 amino acid sequences, as shown in Fig. 1A, the following specific PCR primer set was used for PCR: 5'-AAG CTC TGG TGG AAG GGA AT-3', 594-613, forward, and 5'-AAC AAG GCT GAA CAG GAA CG3', 1120-1101, reverse. After an initial denaturation step (95 C, 5 min), PCR was performed in $10 \mu \mathrm{l}$ of $1 \times$ PCR buffer, $1 \mu \mathrm{l}$ cDNA, $0.2 \mathrm{mM}$ dNTPs, $0.25 \mathrm{U}$ AmpliTaqGold polymerase (Perkin-Elmer Applied Biosystems, Foster City, CA, USA) and $0.25 \mu \mathrm{M}$ of each specific primer. The amplification step consisted of 30 cycles of denaturation (95 C, $1 \mathrm{~min}$ ), annealing (58 C, $1 \mathrm{~min}$ ) and extension (72 C, $1 \mathrm{~min}$ ) before a final extension step of 5 min at $72 \mathrm{C}$. A PCR product of 449 bp was amplified. The PCR product was purified from agarose gel and inserted in the BamHI and NotI sites of the pGEX-6P-1 vector (GE Healthcare UK, Buckinghamshire, UK). After sequencing, host $E$. coli, BL21, carrying the recombinant constructs were grown at $37 \mathrm{C}$ until the log phase and then induced to express the fusion proteins with $0.1 \mathrm{mM}$ isopropyl- $\beta$-D-thiogalactopyranoside (IPTG). After a $24 \mathrm{~h}$ induction period, the bacteria were harvested and sonicated. The recombinant protein was extracted by chromatography using GSTrap HP (GE Healthcare UK, Backinghamshire, UK). Approximately $500 \mu$ g of purified protein was subcutaneously injected 6 times into a female rabbit (Kyudo, Saga, Japan). The resulting antiserum was purified by affinity chromatography using a HiTrap NHS-activated HP column coupled with GST-CDH protein.

\section{Preparation of CVH-GST fusion protein and its antibody}

RNA isolation and cDNA synthesis were performed by the same protocol as production of anti-CDH antibody. In order to produce full length-CVH protein, the following specific PCR primer set was used for PCR: 5'- ATG GAG GAG GAG TGG GAC A-3', 1-19, forward, and 5'- TCT CTT GGG TTC CAT TCT GC-3', 19241943, reverse. After an initial denaturation step (95 C, 5 min), PCR was performed in $10 \mu \mathrm{l}$ of $1 \times$ PCR buffer, $1 \mu \mathrm{l}$ cDNA, $0.2 \mathrm{mM}$ dNTPs, 0.25 U FastTaq DNA polymerase (Roche, Mannheim, Germany) and $0.25 \mu \mathrm{M}$ of each specific primer. The amplification step consisted of 30 cycles of denaturation (95 C, 1 min), annealing (58 C, $1 \mathrm{~min}$ ) and extension (72 C, $1 \mathrm{~min}$ ) before a final extension step of 5 min at 72 C. A PCR product of 1943 bp was amplified. The following process for recombinant protein production was performed as described above. Approximately $1 \mathrm{mg}$ of purified protein was immunized 5 times into a female rat (Kyudo). The resulting antiserum was used for Western blot and immunohistochemical analyses.

\section{Protein extraction and western blot analysis}

Proteins were prepared from the testes, ovaries and spleens of 2 week-old chickens as follows. Each tissue was homogenized in an ice-cold buffer containing $50 \mathrm{mM}$ Tris- $\mathrm{HCl}$ (pH 6.8). The lysates were centrifuged at $13,400 \times \mathrm{g}$ for $15 \mathrm{~min}$ at $4 \mathrm{C}$, and the supernatants were then collected to measure the protein concentration using a BCA kit (Pierce Biotechnology, Rockford, IL, USA). Aliquots of protein (30 $\mu \mathrm{g}$ ) were suspended in $62.5 \mathrm{mM}$ Tris- $\mathrm{HCl}, \mathrm{pH}$ 6.8 , containing $2 \%(\mathrm{w} / \mathrm{v})$ SDS, $10 \%(\mathrm{v} / \mathrm{v})$ glycerol, $0.025 \%(\mathrm{w} / \mathrm{v})$ bromophenol blue and $0.14 \mathrm{M} \beta$-mercaptoethanol, and then treated at $99 \mathrm{C}$ for $3 \mathrm{~min}$. SDS-PAGE was performed on $10 \%(\mathrm{w} / \mathrm{v})$ polyacrylamide gels for immunodetection of $\mathrm{CDH}$, and the gels were then electrotransfered onto Immobilon-PVDF (Millipore, Bedford, MA, USA). Membranes were blocked in TBSE [10 mM Tris-HCl (pH 7.5), $0.15 \mathrm{M} \mathrm{NaCl}, 1 \mathrm{mM}$ EDTA, $0.05 \%$ (v/v) Tween 20] containing $10 \%(\mathrm{w} / \mathrm{v})$ non-fat dry milk, and incubated at $4 \mathrm{C}$ with primary antibodies, polyclonal (affinity purified) anti-CDH antibody (diluted to 1:1,000), anti-CVH antiserum (diluted to 1:3,000) and monoclonal anti- $\alpha$-tubulin antibody DM1A (Sigma-Aldrich, St. Louis, MO, USA), and then incubated with the secondary horseradish peroxidase (HRP)-conjugated goat anti-rabbit IgG antibody (diluted to $1: 2,000$ ), donkey anti-rat IgG antibody (diluted to 1:2,000) and goat anti-mouse IgG antibody (Santa Cruz Biotechnology, Santa Cruz, CA, USA) to detect each protein, respectively. After washing several times, membranes were incubated with LumiGLO (Cell Signaling Technology, Danvers, USA) and exposed to BioMax MS films (Kodak, Rochester, NY, USA) to visualize the bound proteins, as described previously [6]. Analyses using rabbit antibodies preabsorbed with recombinant $\mathrm{CDH}$ protein 

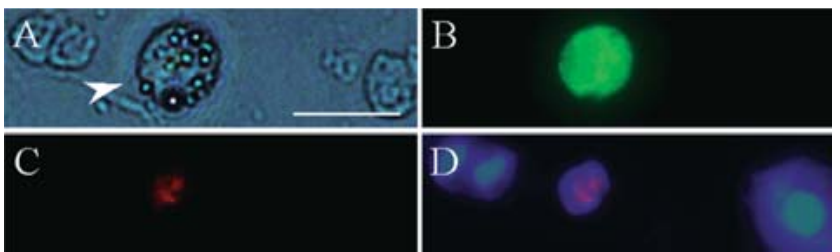

Fig. 2. Immunofluorescence detection for $\mathrm{CDH}$ and $\mathrm{CVH}$ proteins in circulating PGCs at stage 14. A: Bright view of blood cells and PGC. PGC is indicated by an arrowhead. B: Immunostaining with anti-CVH antibody (green). C: Immunostaining with anti$\mathrm{CDH}$ antibody (red). D: CDH and nuclei (blue) merged image. Scale bars $=20 \mu \mathrm{m}$.
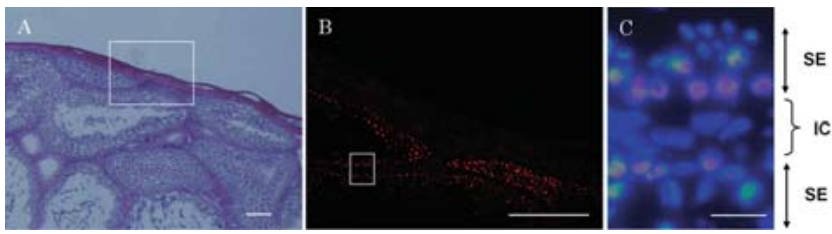

Fig. 3. Immunofluorescence detection for $\mathrm{CDH}$ proteins in the testes of sexually matured chickens. A: HE staining in a section of the testis. The square region shown in panel $\mathrm{A}$ is magnified from a serial section subjected to immunofluorescent studies as shown in B. B: Immunostaining with anti-CDH antibody (red) on a serial section of testis. The square region shown in panel B is magnified in panel C. C: $\mathrm{CDH}$ and nuclei merged image. IC, interstitial cells; SE, seminiferous epithelia. Scale bars=100 (A and B) and10 $\mu \mathrm{m}(\mathrm{C})$.

$(1: 2,000)$ and rat preimmune serum $(1: 3,000)$ were performed to confirm the specificity of antibodies.

\section{Immunofluorescence studies}

Gonads were obtained from male chickens (10 month-old). The tissues were subsequently embedded in an OCT compound, and then $8-\mu \mathrm{m}$ sections were prepared. Blood samples containing PGCs were collected from chicken embryos via a vitelline artery with a fine glass syringe under a microscope at stage 14 [7] and were smeared onto glass slides. Air-dried tissue sections and smeared blood samples containing PGCs were fixed at room temperature for $5 \mathrm{~min}$ in neutral buffered formalin, and nonspecific binding was blocked using $1 \%(\mathrm{v} / \mathrm{v})$ goat serum and $1 \%(\mathrm{w} / \mathrm{v})$ BSA in PBS for $30 \mathrm{~min}$ at room temperature. Sections were incubated for $15 \mathrm{~h}$ at $4 \mathrm{C}$ with the anti-CDH antibody $(1: 100)$ and anti-CVH antiserum (1:300). Rabbit antibodies preabsorbed with recombinant CDH protein (1:100) and rat preimmune serum (1:300) were used as the respective negative controls. After washing with PBS, the sections were incubated with the second antibody, alexa 594conjugated goat anti-rabbit IgG antibody (1:250) and alexa 488conjugated goat anti-rat IgG antibody for $1 \mathrm{~h}$ at room temperature. The sections were subsequently washed in PBS and mounted with Mount-Quick Aqueous (Daido Sangyo, Tokyo, Japan). Immunostaining was detected under a fluorescence microscope (Nikon, Tokyo, Japan).

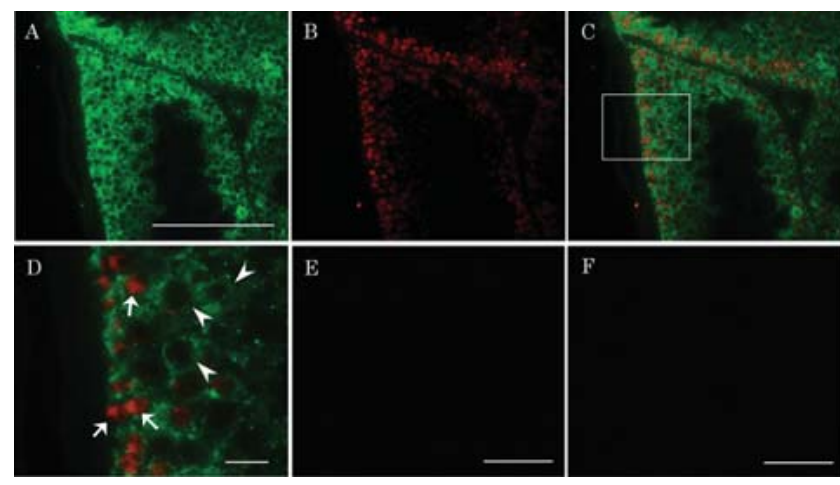

Fig. 4. Immunofluorescence detection for the $\mathrm{CDH}$ and $\mathrm{CVH}$ proteins in the testes of sexually mature chickens. A: Immunostaining with anti-CVH antibody (green) on a section of testis. B: Immunostaining with anti-CDH antibody (red) on a section of testis. C: $\mathrm{CVH}$ and $\mathrm{CDH}$ merged image. D: Magnified $\mathrm{CVH}$ and $\mathrm{CDH}$ merged image of the square regions shown in panels $\mathrm{C}$. Arrows: germ cells strongly positive for both the $\mathrm{CVH}$ and $\mathrm{CDH}$ proteins. Arrowheads: germ cells with negative or very weak $\mathrm{CDH}$ staining. E: Immunostaining with preabsorbed anti-CDH antibody. F: Immunostaining with preimmune rat serum. Scale bars=100 (A-C, E, F) and $10 \mu \mathrm{m}$ (D).

\section{Results}

\section{Expression of CDH protein in the testis and ovary}

Western blot analysis was first performed to detect expression of $\mathrm{CDH}$ protein in the testes and ovaries of 2 week-old chickens. As shown in Fig. 1B, a single band of approximately $60 \mathrm{kDa}$ was detected in both gonads. In accordance with a previous study [8], a single band of $80 \mathrm{kDa}$ was detected in both gonads using anti-CVH antibody. The spleen was negative for both the $\mathrm{CDH}$ and $\mathrm{CVH}$ proteins. These bands were not detected by western blot analysis using preabsorbed anti-CDH antibody or preimmune rat serum, as shown in Fig. 1C.

\section{CDH expression in circulating primordial germ cells}

Chicken PGCs circulating in the bloodstream were easily identified by their morphological features, including a their relatively large diameter, large nucleus, and the presence of a considerable amount of refractive granules in the cytoplasm, as shown in Fig. 2A (arrowheads) and a previous study [9]. The immunofluorescence studies revealed that the circulating PGCs were positive for both the $\mathrm{CDH}$ and $\mathrm{CVH}$ proteins (Fig. 2B and $\mathrm{C}$ ). $\mathrm{CDH}$ protein was exclusively localized in the nuclei of circulating PGCs (Fig. 2D). Conversely, $\mathrm{CVH}$ protein was detected in the cytoplasm, as reported by a previous study [8].

\section{Expression of $\mathrm{CDH}$ protein in mature testis}

Immunofluorescence studies using the testes of mature chickens were performed to evaluate the expression and subcellular localization of $\mathrm{CDH}$ protein. $\mathrm{CDH}$ protein was exclusively localized in the nuclei of germ cells in the seminiferous epithelium, but were not localized in somatic cells such as interstitial cells (Fig. 3B). In particular, the germ cells along the basement membrane were strongly 
positive for $\mathrm{CDH}$ protein (Fig. 3C). In the double immunofluorescent staining using both anti-CVH and anti-CDH antibodies, $\mathrm{CVH}$ was localized in the cytoplasm, while $\mathrm{CDH}$ was localized in the nuclei (Fig. 4A-C). Most of the germ cells distributed on the basal side of the seminiferous epithelium including spermatogonia, were positive for both the $\mathrm{CVH}$ and $\mathrm{CDH}$ proteins (Fig. 4D, arrows). However, no or very weak $\mathrm{CDH}$ signals were detected in some $\mathrm{CVH}$ positive cells on the luminal side (Fig. 4D, arrowheads). Both the $\mathrm{CDH}$ and $\mathrm{CVH}$ proteins were negative in the sections of mature testis using rabbit antibodies preabsorbed with recombinant $\mathrm{CDH}$ protein or preimmune rat serum (Fig. 4E and F).

\section{Discussion}

Our previous study demonstrated that $C D H$ mRNA expression is highly specific to PGCs during early embryonic stages [2]. In the present study, a polyclonal anti-CDH antibody was raised for investigation of $\mathrm{CDH}$ protein expression and its subcelluler localization in germ cells. $\mathrm{CDH}$, as well as the dead end homologues found in other species, has an RNA binding motif in its N-terminal half. The RNA binding motif in Dead end is commonly found in a large variety of RNA binding proteins, such as heterogeneous nuclear ribonucleoproteins (hnRNPs), small nuclear ribonucleoproteins (snRNPs) and other pre-RNA and mRNA-associated proteins [1]. In mice, Dead end is actually highly homologous to another RNA binding protein, APOBEC-1 complementation factor (ACF) $[3,4,10,11]$. Therefore, we raised a specific antibody against $\mathrm{C}$ terminal recombinant $\mathrm{CDH}$ protein without the RNA binding motif. Immunoblotting analysis showed that a single band of approximately $60 \mathrm{kDa}$ was detected in the ovary and testis. However, the molecular size was larger than that of the deduced amino acid sequence reported in our previous study [2]. It is likely that $\mathrm{CDH}$ is modified at post-transcriptional sites or its isoforms are produced because of alternative splicing. Indeed, $\mathrm{CDH}$ protein has an $\mathrm{N}$-glycosylation site [2]. It has been reported that the dead end gene encodes two isoforms in mice (DND1- $\alpha$ and DND1- $\beta$ ), as a result of alternative splicing, and that the molecular size of DND1$\beta$ is larger than its theoretical size [4].

$\mathrm{CDH}$ protein was consistently localized in the nuclei of PGCs circulating in the bloodstream and in the germ cells of the testis and ovary (data not shown). These results strongly suggest that it functions as a nucleoprotein in germ cells. Interestingly, in the mature testis, spermatogonia accumulate more $\mathrm{CDH}$ protein than other germ cells such as spermatids and spermatozoa. This suggests that $\mathrm{CDH}$ is related to spermatogenesis, meiosis and stem cell performance.

$\mathrm{CVH}$ is another well-known chicken germ cell protein [8]. Like $\mathrm{CDH}, \mathrm{CVH}$ has a putative RNA-binding motif consisting of RGG (Arg-Gly-Gly)-box repeats [12]. In contrast to $\mathrm{CDH}$ protein, $\mathrm{CVH}$ protein is localized in the cytoplasm of PGCs and germ cells in the testis and ovary at latter stages. The CVH protein in germ cells is associated with some cytoplasmic structure. Especially in oocytes, it colocalizes with spectrin and mitochondrial cloud. In mice, vasa is also localized in the cytoplasm of germ cells [13]. It is also known that other germ cell-specific proteins, such as nanos and $t r d r$, are predominantly localized in the cytoplasm of germ cells
$[14,15]$, although these chicken homologue genes have not yet been investigated. Whereas vasa, nanos and $t r d r$ are conserved among many species, including drosophila, dead end orthologs have not been identified in invertebrates [1]. Considering this difference in subcellular localization and the lack of dead end orthologs in invertebrates, the localization of $\mathrm{CDH}$ in the nucleus found in the present study raises the possibility that its function differs compared with the cytoplasmic RNA binding proteins described above.

There is some information available in the literature concerning the function of Dead end. In zebrafish, knockdown of dead end by antisense oligonucleotides results in abnormal migration and fragmentation of PGCs [1]. Genetic inactivation of dead end in mice causes the lack of PGC and increases the incidence of testicular germ cell tumor and embryonic lethality in the 129 mouse strains $[3,4]$. Furthermore, a recent study shows that Dead end protein prevents miRNA from silencing expression of germ cell-specific genes such as nanos and trdr7 in zebrafish PGCs by binding to the uridine-rich region at 3'UTR of mRNA, which is near the miRNA targeting site [5]. Given that CDH protein is localized in the nuclei of germ cells, it may work on some mRNAs transcribed in the nuclei before they are transported to the cytoplasm, in which mRNAs are exposed to translational regulation factors such as mature miRNA [16-18].

Subcellular localization of Dead end protein in other species has mainly been observed by transfection of a GFP-Dead end fusion construct into several cell types [1, 4]. It has been reported that GFP-Dead end fusion protein driven by nos 1-3'UTR was localized in the perinuclear germ plasm of zebrafish PGCs at the 10somite stage [1]. This was the dame localization as that of Vasa in their study. This is different from the localization patterns of Dead end and Vasa in the chicken according to our current observations and a previous study of CVH [8]. Dead end may have a speciesspecific localization manner or its localization pattern may be vary considerably in association with the cell status at the developmental stage. In fact, it has been reported that GFP-mouse DND1 is localized in the cytoplasm and nuclei of COS-7 and HeLa cells, respectively [4]. Thus, the subcellular localization of Dead end protein may depend on cell type. Considering this difference in $\mathrm{CDH}$ localization, more comprehensive studies are required in all species. An RNA binding protein, ACF, is known to have high homology with dead end $[3,4,10,11]$. In addition, ACF is localized almost exclusively in the nucleus when an epitope-tagged protein is expressed in vitro $[19,20]$. ACF has both a canonical SV40-like nuclear localization signal and a novel 41-residue nuclear localization signal (ANS) [21], whereas Dead end lacks known nuclear localization signals [4]. Therefore, dead end may have a novel system enabling translocation to the nuclei. Our current findings will contribute to clarification of the translocation of Dead end protein.

\section{Acknowledgements}

This work was funded by a Grant-in-Aid for Scientific Research (19658099) and a Research Fellowship for Young Scientists (No. 09744) from the Japan Society for the Promotion of Sciences. We 
are grateful to Dr. C Wood (Zhejiang University, Hangzhou, China) for critical reading of the manuscript.

\section{References}

1. Weidinger G, Stebler J, Slanchev K, Dumstrei K, Wise C, Lovell-Badge R, Thisse C, Thisse B, Raz E. Dead end, a novel vertebrate germ plasm component, is required for zebrafish primordial germ cell migration and survival. Curr Biol 2003; 13: 1429-1434.

2. Aramaki S, Sato F, Kato T, Soh T, Kato Y, Hattori M-A. Molecular cloning and expression of dead end homologue in chicken primordial germ cells. Cell Tissue Res 2007; 330: 45-52.

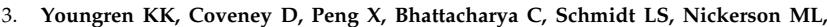
Lamb BT, Deng JM, Behringer RR, Capel B, Rubin EM, Nadeau JH, Matin A. The Ter mutation in the dead end gene causes germ cell loss and testicular germ cell tumours. Nature 2005; 435: 360-364

4. Bhattacharya C, Aggarwal S, Zhu R, Kumar M, Zhao M, Meistrich ML, Matin A. The mouse dead-end gene isoform alpha is necessary for germ cell and embryonic viability. Biochem Biophys Res Commun 2007; 355: 194-199.

5. Kedde M, Strasser MJ, Boldajipour B, Vrielink JA, Slanchev K, le Sage C, Nagel R, Voorhoeve PM, van Duijse J, Ørom UA, Lund AH, Perrakis A, Raz E, Agami R. RNA-binding protein Dnd1 inhibits microRNA access to target mRNA. Cell 2007; 131: 1273-1286.

6. Sato F, Kurokawa M, Yamauchi N, Hattori M-A. Gene silencing of myostatin in differentiation of chicken embryonic myoblasts by small interfering RNA. Am J Physiol Cell Physiol 2006; 291: C538-545.

7. Hamburger V, Hamilton HL. A series of normal stages in the development of the chick embryo. J Morphol 1951; 88: 49-92.

8. Tsunekawa N, Naito M, Sakai Y, Nishida T, Noce T. Isolation of chicken vasa homolog gene and tracing the origin of primordial germ cells. Development 2000; 127 : 2741-2750.

9. Fujimoto T, Ninomiya T, Ukeshima A. Observations of primordial germ-cells in blood samples from chick-embryo. Dev Biol 1976; 49: 278-282.

10. Matin A, Nadeau JH. Search for testicular cancer gene hits dead-end. Cell Cycle 2005 4: 1000-1002.

11. Matin A. What leads from dead-end? Cell Mol Life Sci 2007; 64: 1317-1322.

12. Kiledijian M, Dreyfuss G. Primary structure and binding activity of the hnRNP U protein: binding RNA through RGG box. EMBO J 1992; 11: 2655-2664.

13. Toyooka Y, Tsunekawa N, Takahashi Y, Matsui Y, Satoh M, Noce T. Expression and intracellular localization of mouse Vasa-homologue protein during germ cell development. Mech Dev 2000; 93: 139-149.

14. Chuma S, Hiyoshi M, Yamamoto A, Hosokawa M, Takamune K, Nakatsuji N Mouse Tudor Repeat-1 (MTR-1) is a novel component of chromatoid bodies/nuages in male germ cells and forms a complex with snRNPs. Mech Dev 2003; 120: 979-990.

15. Aoki Y, Nagao I, Saito D, Ebe Y, Kinjo M, Tanaka M. Temporal and spatial localization of three germline-specific proteins in medaka. Dev Dyn 2008; 237: 800-807.

16. Bohnsack MT, Czaplinski K, Gorlich D. Exportin 5 is a RanGTP-dependent dsRNAbinding protein that mediates nuclear export of pre-miRNAs. RNA 2004; 10: 185-191.

17. Gregory RI, Yan KP, Amuthan G, Chendrimada T, Doratotaj B, Cooch N, Shiekhat $\operatorname{tar} \mathbf{R}$. The microprocessor complex mediates the genesis of microRNAs. Nature 2004 432: 235-240.

18. Maniataki E, Mourelatos Z. A human, ATP-independent, RISC assembly machine fueled by pre-miRNA. Genes Dev 2005; 19: 2979-2990.

19. Blanc V, Henderson JO, Kennedy S, Davidson NO. Mutagenesis of apobec-1 complementation factor reveals distinct domains that modulate RNA binding, proteinprotein interaction with apobec-1, and complementation of C to U RNA-editing activity. J Biol Chem 2001; 276: 46386-46393.

20. Blanc V, Navaratnam N, Henderson JO, Anant S, Kennedy S, Jarmuz A, Scott J Davidson NO. Identification of GRY-RBP as an apolipoprotein B RNA-binding protein that interacts with both apobec- 1 and apobec- 1 complementation factor to modulate C to U editing. J Biol Chem 2001; 276: 10272-10283.

21. Blanc V, Kennedy S, Davidson NO. A novel nuclear localization signal in the auxiliary domain of apobec-1 complementation factor regulates nucleocytoplasmic import and shuttling. J Biol Chem 2003; 278: 41198-41204. 